Case Report

\title{
Spontaneous Pneumomediastinum due to Anti-Melanoma Differentiation-Associated Protein 5 Requiring a Bilateral Lung Transplant
}

\author{
Amrit Singh Jhajj $\mathbb{D}^{1},{ }^{1}$ James Hok Shun Yeung $\left(\mathbb{D},{ }^{2}\right.$ and Fergus To ${ }^{2}{ }^{2}$ \\ ${ }^{1}$ Department of Medicine, University of British Columbia, Vancouver, Canada \\ ${ }^{2}$ Division of Rheumatology, University of British Columbia, Vancouver, Canada \\ Correspondence should be addressed to Amrit Singh Jhajj; ajhajj93@alumni.ubc.ca
}

Received 30 August 2021; Revised 19 October 2021; Accepted 20 October 2021; Published 29 October 2021

Academic Editor: Gregory J. Tsay

Copyright (c) 2021 Amrit Singh Jhajj et al. This is an open access article distributed under the Creative Commons Attribution License, which permits unrestricted use, distribution, and reproduction in any medium, provided the original work is properly cited.

\begin{abstract}
Anti-melanoma differentiation-associated protein 5 (anti-MDA5) is a subset of dermatomyositis associated with respiratory complications, in which rapidly progressive interstitial lung disease (RPILD) is commonly cited, and spontaneous pneumomediastinum (SPM) is a rare complication. In medical literature, aggressive immunosuppressive therapy has been the mainstay of anti-MDA5-associated SPM management. Here, we report the first MDA5 case with SPM which was successfully treated with a double-lung transplant. We present a 48-year-old male who presented with multiple constitutional symptoms such as fevers, weight loss, malaise, and arthralgias, in association with erythroderma over the ears and fingers. Imaging of the chest demonstrated peripheral airspace disease, and myositis-specific serology returned positive for anti-Jo1 (medium-positive), anti-Ro52 (high-positive), and anti-MDA5 (weak-positive) autoantibodies. Therefore, the patient was begun on immunosuppressive therapy as the leading diagnosis included autoimmune myositis, possibly antisynthetase syndrome with interstitial lung disease (ILD). A year later, the patient presented with progressive shortness of breath, widespread macular erythematous facial rash, and new erythematous ulcerations over the fingertips. Imaging demonstrated a new SPM at this juncture. As the patient's respiratory status continued to decline despite the use of immunosuppressive agents, a double-lung transplant was performed. Therefore, we propose that lung transplantation should be considered early in MDA5-SPM.
\end{abstract}

\section{Introduction}

Autoantibodies (Abs) are increasingly recognized for their pivotal role in the diagnosis and prognosis of inflammatory myopathies. Dermatomyositis can be subclassified according to particular Abs, one of which is anti-melanoma differentiation-associated protein 5 (anti-MDA5), seen in 10-35\% of cases [1]. Anti-MDA5 is reported to be an independent risk factor for interstitial lung disease- (ILD-) associated mortality [2]. Although typically associated with clinical amyopathic dermatomyositis (CADM), 42.9-54.5\% antiMDA5 patients can demonstrate overt clinical myopathy $[1,3]$. Anti-MDA5 is associated with respiratory complications such as rapidly progressive interstitial lung disease (RPILD) and, as a rare sequalae, spontaneous pneumomediastinum (SPM) $[4,5]$. SPM is characterized as free air around the mediastinal structures with an associated prevalence of $2.2 \%$ in all myositis cases and a striking mortality rate of $25 \%$ within the first month of diagnosis [6]. In this report, we describe the first anti-MDA5 case with SPM which was successfully treated with a double-lung transplant.

\section{Case Presentation}

A 48-year-old diabetic male presented in May 2019 with cough, low-grade fevers, erythroderma over the ears and radial aspect of his fingers (without mechanics hands), 20pound weight loss, and arthralgias. Blood work was remarkable for a ferritin of $2100 \mathrm{ug} / \mathrm{L}$ (normal 15-300 ug/L), 


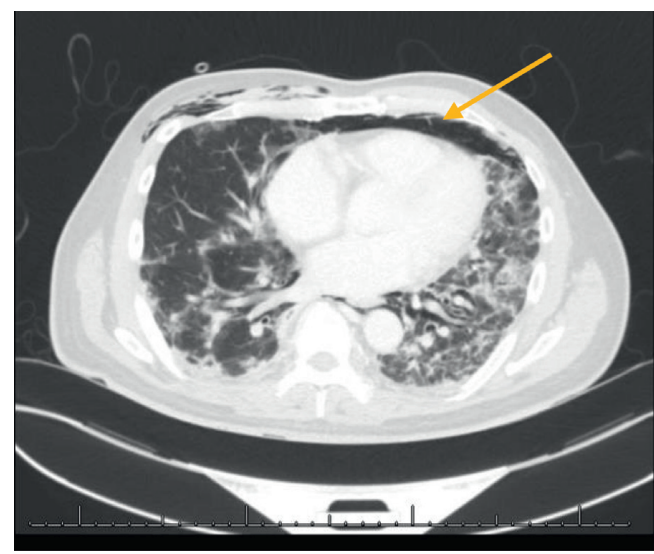

Figure 1: Lung CT scan demonstrating SPM (arrow) prior to lung transplant.

ALT of $83 \mathrm{U} / \mathrm{L}$ (normal $<55 \mathrm{U} / \mathrm{L}$ ), LDH of $302 \mathrm{U} / \mathrm{L}$ (normal 90-240 U/L), CK of $245 \mathrm{U} / \mathrm{L}$ (normal $<165 \mathrm{U} / \mathrm{L}$ ), and positive anti-scl70 Abs $177 \mathrm{U} / \mathrm{mL}$ (normal $<100 \mathrm{U} / \mathrm{mL}$ ). CT imaging demonstrated patchy multifocal areas of peripheral airspace disease in the lungs with moderate fatty liver infiltration. Prednisone was initiated empirically at $65 \mathrm{mg}$ daily. A week later, a bronchoscopy was performed and was unremarkable. At this time, the differential diagnosis included systemic sclerosis versus relapsing polychondritis, and therefore, prednisone (50 $\mathrm{mg}$ daily) and azathioprine (150 mg daily) were begun.

A month later, as prednisone was tapered down to $10 \mathrm{mg}$ daily, the patient experienced increasing respiratory symptoms with new proximal lower limb muscle weakness. CK was $801 \mathrm{U} / \mathrm{L}$ (normal $<165 \mathrm{U} / \mathrm{L}$ ), and MRI imaging demonstrated edema in the hip and shoulder girdles. Serology for myositis-specific and -associated Abs using line blot immunoassay (EUROLINE Inflammatory Myopathies 16Ag (IgG) (Euroimmun, Lubeck, Germany)) was positive for anti-Jo1 (medium-positive), anti-Ro52 (high-positive), anti-MDA5 (weak-positive), and anti-NT5c1A Abs (no titres provided by assay). Given these findings, autoimmune myositis was considered, possibly antisynthetase syndrome with ILD given the anti-Jo1 positivity. The weakly positive anti-MDA5 was of unclear significance at that juncture. Treatment was modified to prednisone $65 \mathrm{mg}$ daily with taper, mycophenolate $1 \mathrm{~g}$ twice daily (uptitrated to $1.5 \mathrm{~g}$ twice daily), and hydroxychloroquine $300 \mathrm{mg}$ daily. By August 2019, no myopathy was detected on electromyography and prior skin lesions had improved. In June 2020, he presented with progressive shortness of breath and widespread macular erythematous rashes over his face, with new erythematous ulcerations over the fingertips. MDA5 dermatomyositis was then diagnosed as his clinical phenotype was more in keeping of that than antisynthetase syndrome. A CT scan found extensive subcutaneous emphysema within the upper chest and extensive contiguous pneumomediastinum (Figure 1). IV methylprednisolone (1 gram daily for 3 days) and antibiotics were started, hydroxychloroquine was continued, and mycophenolate was held. His oxygen demands climbed to $55 \% \mathrm{FiO}_{2}$. His respiratory

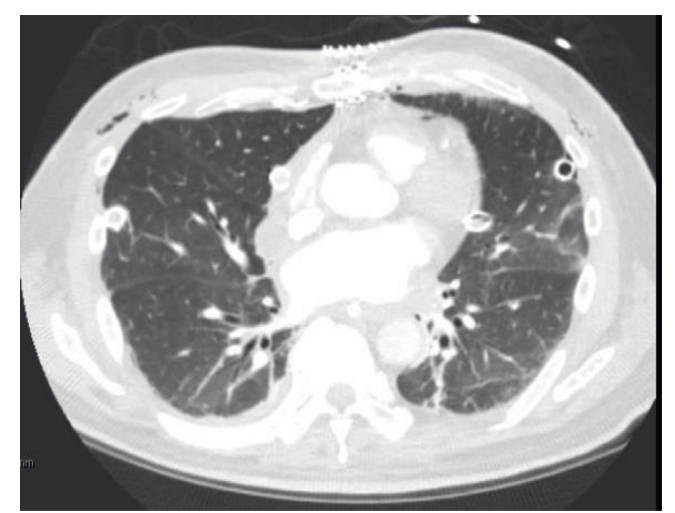

Figure 2: Lung CT scan after bilateral lung transplant.

status continued to decline despite rituximab 1 gram IV, and he went on to require intubation with extracorporeal membrane oxygenation (ECMO). A double-lung transplant was performed 2 days later (Figure 2).

Postoperatively, he was able to taper off oxygen and has remained on room air since. On recovery, investigations have demonstrated the presence of critical illness myopathy without any active myositis. He is currently undergoing intensive inpatient rehabilitation with positive interim results. He remains on tacrolimus $3.5 \mathrm{mg}$ in AM and $3 \mathrm{mg}$ in PM, mycophenolate 1 gram twice daily, and prednisone $15 \mathrm{mg}$ daily for post-lung-transplant therapy.

\section{Discussion}

While there are case reports of lung transplant rescue therapy in MDA5-RPILD (Table 1), to our knowledge, this is the first published case of MDA5-SPM successfully treated with a double-lung transplant. Predictors of poor outcomes in SPM, apart from ILD, include cutaneous vasculopathy, elevated ferritin, anti-Ro-52, and anti-MDA5, factors that were all present in our case [7-9]. The association of clinical variables such as cutaneous vasculopathy and ferritin rise could suggest either an underlying endothelial inflammatory process or coagulation-fibrinolytic system mounting a response in the pathogenesis of SPM-related DM, both of which may guide future therapeutic development $[5,9,10]$.

This case also highlights the diagnostic dilemma of managing of concurrent myositis specific autoantibodies (MSAs). Both anti-MDA5 and anti-Jo1 Abs are MSA, which are noted to be exclusive in $99.8 \%$ of cases and carry $91.9 \%$ false positive rate when only weakly positive $[11,12]$. As such, given anti-MDA5 was only weakly positive, the antiJo1 was felt to be the true positive initially, leading a working diagnosis of antisynthetase syndrome with ILD. The eventual change in his clinical presentation makes it unlikely that this patient's disease, including ILD, is due to antisynthetase syndrome. His ulcerative cutaneous lesions are much more commonly detected in anti-MDA5 dermatomyositis [13]. Moreover, the speed of this patient's ILD progression is much more characteristic of anti-MDA-5 than antisynthetase syndrome [14]. The anti-MDA5 MSA result represents a true positive, rather than the anti-Jo1, albeit 
TABLE 1: Lung transplant rescue therapy in MDA5-RPILD case reports.

\begin{tabular}{|c|c|c|c|c|c|}
\hline Reference & Country & $\begin{array}{c}\text { Patient } \\
\text { demographics }\end{array}$ & Clinical features & Positive biomarkers & Outcome \\
\hline $\begin{array}{l}\text { Deitchman } \\
\text { et al. }[16]\end{array}$ & USA & $\begin{array}{l}\text { 51-year-old } \\
\text { male }\end{array}$ & Small joint arthralgias, cough, dyspnea & Anti-MDA5 & $\begin{array}{l}\text { Bilateral lung } \\
\text { transplant }\end{array}$ \\
\hline Huang et al. [1] & Canada & $\begin{array}{l}\text { 52-year-old } \\
\text { male }\end{array}$ & $\begin{array}{c}\text { Heliotrope rash, Gottron's papule, periungal } \\
\text { erythema }\end{array}$ & $\begin{array}{l}\text { Anti-RO52, anti- } \\
\text { MDA5 }\end{array}$ & $\begin{array}{l}\text { Bilateral lung } \\
\text { transplant }\end{array}$ \\
\hline Huang et al. [1] & Canada & $\begin{array}{l}\text { 54-year-old } \\
\text { female }\end{array}$ & Heliotrope rash, Gottron's papule, cutaneous ulcers & $\begin{array}{l}\text { Anti-RO52, anti- } \\
\text { MDA5, OJ }\end{array}$ & $\begin{array}{l}\text { Bilateral lung } \\
\text { transplant }\end{array}$ \\
\hline Huang et al. [1] & Canada & $\begin{array}{l}\text { 59-year-old } \\
\text { female }\end{array}$ & Palmar papules, periungal erythema & $\begin{array}{l}\text { Anti-RO52, anti- } \\
\text { MDA5 }\end{array}$ & $\begin{array}{c}\text { Bilateral lung } \\
\text { transplant }\end{array}$ \\
\hline Leclair et al. [8] & USA & $\begin{array}{l}\text { 38-year-old } \\
\text { male }\end{array}$ & $\begin{array}{l}\text { Heliotrope rash, Gottron's papules, periungal } \\
\text { erythema, buccal mucosa erosions, mechanic's } \\
\text { hands, arthralgia, exertional dyspnea }\end{array}$ & $\begin{array}{l}\text { Anti-RO52, anti- } \\
\text { MDA5 }\end{array}$ & $\begin{array}{l}\text { Bilateral lung } \\
\text { transplant }\end{array}$ \\
\hline $\begin{array}{l}\text { Takada et al. } \\
\text { [17] }\end{array}$ & USA & $\begin{array}{l}\text { 42-year-old } \\
\text { female }\end{array}$ & Rash to the face and hands, leg weakness, dyspnea & $\begin{array}{l}\text { Anti-smooth-muscle } \\
\text { antibody, serum IgG, }\end{array}$ & $\begin{array}{c}\text { Bilateral lung } \\
\text { transplant }\end{array}$ \\
\hline Pacot et al. [7] & France & $\begin{array}{l}\text { 51-year-old } \\
\text { male }\end{array}$ & Acute dyspnea & $\begin{array}{l}\text { Anti-MDA5, } \\
\text { cytoplasmic islets }\end{array}$ & $\begin{array}{l}\text { Bilateral lung } \\
\text { transplant }\end{array}$ \\
\hline Shoji et al. [18] & Japan & $\begin{array}{l}\text { 52-year-old } \\
\text { female }\end{array}$ & Gottron's papules, dyspnea & Anti-MDA5 & $\begin{array}{l}\text { Bilateral lung } \\
\text { transplant }\end{array}$ \\
\hline
\end{tabular}

only weakly positive. Therefore, it is imperative that complications of all MSA be monitored early, regardless of strength, as even a concurrent, weakly positive anti-MDA5 $\mathrm{Ab}$ ultimately led to bilateral lung transplantation.

Prompt diagnosis and intervention is crucial in MDA5SPM, as mortality in anti-MDA5-positive cases with and without SPM has been reported to be $60 \%$ and $37 \%$, respectively $[15,16]$. Early aggressive immunosuppressive therapy and ECMO have been the mainstay treatment of MDA5-SPM. Supplementary ventilation options such as noninvasive positive pressure ventilation (NPPV) are futile given NPPV has been shown to aggravate mediastinal emphysema [15]. In one MDA5-SPM study, mortality was $100 \%$ in patients treated with NPPV in comparison to $49 \%$ in patients treated without NPPV at 100 days [15]. SPM likely occurs through the Macklin effect of alveolar rupture with retrograde air dissection along the bronchovascular sheath towards the mediastinum. As such, NPPV likely exacerbates the inappropriate outflow of air $[9,15]$. Therefore, we propose that, similar to RPILD, lung transplantation should be considered early on in the management of MDA5-SPM.

\section{Abbreviations}

$\begin{array}{ll}\text { Abs: } & \text { Autoantibodies } \\ \text { Anti- } & \text { Anti-melanoma differentiation-associated } \\ \text { MDA5: } & \text { protein 5 } \\ \text { ILD: } & \text { Interstitial lung disease } \\ \text { CADM: } & \text { Clinical amyopathic dermatomyositis } \\ \text { RPILD: } & \text { Rapidly progressive interstitial lung disease } \\ \text { SPM: } & \text { Spontaneous pneumomediastinum } \\ \text { CT: } & \text { Computerized tomography } \\ \text { CK: } & \text { Creatinine kinase } \\ \text { LDH: } & \text { Lactate dehydrogenase } \\ \text { ALT: } & \text { Alanine aminotransferase } \\ \text { ECHMO: } & \text { Extracorporeal membrane oxygenation } \\ \text { NPPV: } & \text { Noninvasive positive pressure ventilation }\end{array}$

MSA: $\quad$ Myositis specific autoantibodies.

\section{Conflicts of Interest}

The authors declare no conflicts of interest.

\section{References}

[1] K. Huang, O. Vinik, K. Shojania et al., "Clinical spectrum and therapeutics in Canadian patients with anti-melanoma differentiation-associated gene 5 (MDA5)-positive dermatomyositis: a case-based review," Rheumatology International, vol. 39, no. 11, pp. 1971-1981, 2019.

[2] M. Yashiro, T. Asano, S. Sato et al., "Anti-MDA5 antibodypositive hypomyopathic dermatomyositis complicated with pneumomediastinum," Fukushima Journal of Medical Science, vol. 64, no. 2, pp. 89-94, 2018.

[3] J. C. Hall, L. Casciola-Rosen, L.-A. Samedy et al., "Antimelanoma differentiation-associated protein 5-associated dermatomyositis: expanding the clinical spectrum," Arthritis Care \& Research, vol. 65, no. 8, pp. 1307-1315, 2013.

[4] M. J. Bendewald, D. A. Wetter, X. Li, and M. D. P. Davis, "Incidence of dermatomyositis and clinically amyopathic dermatomyositis," Archives of Dermatology, vol. 146, no. 1, pp. 26-30, 2010.

[5] C. W. S. Chan, H. Y. Chung, C. S. Lau, and H. H. L. Tsang, "Spontaneous pneumomediastinum in a dermatomyositis patient with anti-melanoma differentiation-associated gene-5 antibody and interstitial lung disease despite an initial response to immunosuppressant," International Journal of Rheumatic Diseases, vol. 22, no. 3, pp. 521-524, 2019.

[6] B. Le Goff, P. Chérin, A. Cantagrel et al., "Pneumomediastinum in interstitial lung disease associated with dermatomyositis and polymyositis," Arthritis Care \& Research, vol. 61, no. 1, pp. 108-118, 2009.

[7] L. Pacot, J. Pouchot, N. De Prost et al., "Interstitial lung disease-complicated anti-MDA5 antibody in clinically amyopathic dermatomyositis patients: report of two cases with distinct clinical features," Frontiers of Medicine, vol. 7, pp. 1-5, 2020. 
[8] V. Leclair, A. Labirua-Iturburu, and I. E. Lundberg, "Successful lung transplantation in a case of rapidly progressive interstitial lung disease associated with antimelanoma differentiation-associated gene 5 antibodies," Journal of Rheumatology, vol. 45, no. 4, pp. 581-583, 2018.

[9] C. Oberg, R. Hiensch, and S. Dua, "Dermatomyositis and associated vasculopathy causing tracheal necrosis and spontaneous pneumomediastinum," American Journal of Respiratory and Critical Care Medicine, vol. 195, 2017.

[10] X. Ma, Z. Chen, W. Hu et al., "Clinical and serological features of patients with dermatomyositis complicated by spontaneous pneumomediastinum," Clinical Rheumatology, vol. 35, no. 2, pp. 489-493, 2016.

[11] F. To, C. Ventín-Rodríguez, S. Elkhalifa, J. B. Lilleker, and H. Chinoy, "Line blot immunoassays in idiopathic inflammatory myopathies: retrospective review of diagnostic accuracy and factors predicting true positive results," $B M C$ Rheumatology, vol. 4, no. 1, pp. 1-8, 2020.

[12] Z. Betteridge, S. Tansley, G. Shaddick et al., "Frequency, mutual exclusivity and clinical associations of myositis autoantibodies in a combined European cohort of idiopathic inflammatory myopathy patients," Journal of Autoimmunity, vol. 101, pp. 48-55, 2019.

[13] D. Fiorentino, L. Chung, J. Zwerner, A. Rosen, and L. Casciola-Rosen, "The mucocutaneous and systemic phenotype of dermatomyositis patients with antibodies to MDA5 (CADM-140): a retrospective study," Journal of the American Academy of Dermatology, vol. 65, no. 1, pp. 25-34, 2011.

[14] Y. Allenbach, Y. Uzunhan, S. Toquet et al., "Different phenotypes in dermatomyositis associated with anti-MDA5 antibody," Neurology, vol. 95, no. 1, pp. e70-e78, 2020.

[15] M. Zhou, Y. Ye, N. Yan, X. Lian, C. Bao, and Q. Guo, "Noninvasive positive pressure ventilator deteriorates the outcome of pneumomediastinum in anti-MDA5 antibodypositive clinically amyopathic dermatomyositis," Clinical Rheumatology, vol. 39, no. 6, pp. 1919-1927, 2020.

[16] A. R. Deitchman, O. Kalchiem-Dekel, N. Todd, and R. M. Reed, "Rapidly progressive interstitial lung disease due to anti-melanoma differentiation associated protein-5 requiring a bilateral lung transplant, and complicated by kennel cough," Respiratory Medicine Case Reports, vol. 28, Article ID 100886, 2019.

[17] T. Takada, K. Asakawa, and R. Barrios, "A Japanese-American female with rapidly progressive interstitial lung disease associated with clinically amyopathic dermatomyositis," Clinical Rheumatology, vol. 40, no. 3, pp. 1159-1165, 2021.

[18] T. Shoji, T. Bando, T. Fujinaga et al., "Living-donor lobar lung transplantation for rapidly progressive interstitial pneumonia associated with clinically amyopathic dermatomyositis: report of a case," General Thoracic and Cardiovascular Surgery, vol. 61, no. 1, pp. 32-34, 2013. 